\title{
Effect of Alpha-lipoic Acid Supplementation on Glycemic Control in the Patients with Metabolic Syndrome: A Randomized Clinical Trial
}

Nafiseh Kaviyani

Islamic Azad University East Tehran Branch

Seyed Ali Keshavarz

University of Tehran

Behnood Abbasi ( $\sim$ abbasi.b@srbiau.ac.ir)

Islamic Azad University East Tehran Branch https://orcid.org/0000-0002-7684-3691

\section{Research}

Keywords: metabolic syndrome, alpha-lipoic acid, blood glucose, insulin resistance, HbA1c

Posted Date: July 8th, 2020

DOI: https://doi.org/10.21203/rs.3.rs-37045/v1

License: (c) (i) This work is licensed under a Creative Commons Attribution 4.0 International License.

Read Full License 


\section{Abstract}

\section{Background}

Metabolic syndrome is a collection of metabolic disorders. It is an important risk factor for progression towards type 2 diabetes and coronary artery diseases. Alpha-lipoic acid also plays a role as a co-factor for multi-enzyme complexes catalyzing oxidative. Antioxidant properties of alpha-lipoic acid (ALA) are associated with insulin-like effects. The present study examined the effect of alpha-lipoic acid supplementation on glycemic control in the patients with metabolic syndrome.

\section{Methods}

A total of 46 patients with metabolic syndrome have participated in this double-blind randomized parallelgroup clinical trial, 23 patients in one group received $600 \mathrm{mg}$ of alpha-lipoic acid supplement and 23 patients in another group received the placebo for 12 weeks. RCT protocol was registered at ClinicalTrials.gov and it is available using NCT03589690 code. Fasting blood sugar (FBS), Serum insulin, Hemoglobin $\mathrm{A} 1 \mathrm{c}(\mathrm{HbA} 1 \mathrm{c})$, insulin resistance, were measured at the beginning and the end of the study. Dietary intake of participants was examined at the beginning of the study and this information was evaluated using Nutritionist 4 (N4) software. Studied information was analyzed by SPSS-24 software.

Results

There were significant decreases in FBS levels $(P=0.009)$, serum insulin $(P=0.02)$, and insulin resistance $(P=0.001)$ between the two groups. Also, the HbA1c levels $(P=0.16)$ had no significant difference between the two groups.

\section{Conclusion}

ALA is a potent antioxidant that it might be able to improve the blood glucose levels, serum insulin and insulin resistance; thus it will have positive effects on promoting the health levels in the patients with metabolic syndrome.

Trial registration

NCT03589690

\section{Background}

Due to urbanization, excessive energy intake, increased obesity, and sedentary lifestyle; metabolic syndrome has become one of the leading public health concerns worldwide (1). Central obesity, dyslipidemia, increase in high-density lipoprotein cholesterol levels, high serum triglyceride, insulin resistance, and type 2 diabetes are also some of the risk factors for metabolic syndrome (2). The patients with metabolic syndrome have a higher risk for various types of diseases and there are also some 
degrees of disability and mortality in these patients (3). According to the National Cholesterol Education Program Adult Treatment Panel III criteria (NCEP ATPIII), at least three of the following criteria are required to diagnose the metabolic syndrome: a waist circumference $\geq 102 \mathrm{~cm}$ in men or $\geq 88 \mathrm{~cm}$ in women, triglycerides $\geq 150 \mathrm{mg} / \mathrm{dl}$ or HDL-C $<40 \mathrm{mg} / \mathrm{dl}$ in men and $<50 \mathrm{mg} / \mathrm{dl}$ in women, hypertension (diastolic blood pressure $\geq 85 \mathrm{mmHg}$ and systolic blood pressure $\geq 130 \mathrm{mmHg}$ or taking anti-hypertensive medication), and blood glucose $\geq 100 \mathrm{mg} / \mathrm{dl}$ (4). According to a study by Alexander, metabolic syndrome annually imposes approximately $\$ 4,000$ cost per person (5). The global prevalence rate of metabolic syndrome is estimated to be about $10-50 \%(6)$.

Alpha-lipoic acid (ALA) or thioctic acid is an eight-carbon compound with two thiol groups (7). ALA levels decreased in the people with diabetes. Some studies, both on diabetic animal models and on the patients with diabetes, have shown beneficial effects of ALA as supplementation on the improvement of glucose metabolism $(8,9)$. This suggests that, treatment with this antioxidant might be able to increase the insulin sensitivity in the patients with metabolic syndrome (10). The antioxidant properties of ALA are associated with insulin-like effects $(11,12)$ and can protect the pancreatic cells against oxidative damage (13). The results of research on the patients with diabetes have shown that, ALA levels in these individuals have been compensated by supplementations and have reduced glucose levels, protein glycosylation, and HbA1c (10). Clinical studies have shown that, administration of ALA up to $1800 \mathrm{mg} /$ day has not been harmful on humans $(14,15)$.

Since hyperglycemia plays an important role in the development and progression of metabolic syndrome and its complications such as cardiovascular disease, type 2 diabetes, and stroke; newer strategies including proposed ALA supplementation are needed to control blood sugar in the patients with metabolic syndrome. Accordingly, the present study examined the effect of ALA supplementation on glycemic control in the patients with metabolic syndrome.

\section{Methods}

\section{Subjects}

The sample size required for the present study was measured according to the previous studies, 21 participants are needed in the intervention group and also 21 participants in the control group. By considering the probability of dropping out of the subjects, 23 participants are required in each group. Inclusion criteria include having at least three of the metabolic syndrome criteria presented in NCEP ATPIII, adults aged from 18 to 60 years old, a complete individual willingness to cooperate in the project, non-pregnancy, non-menopause, not have history of heart attacks and stroke in the last year, not have history of uncontrolled diabetes, not use of any supplement with therapeutic doses that affect the ALA metabolism that is not possible for the person to stop taking it. Exclusion criteria included pregnancy, myocardial infarction, and stroke, diagnosis of uncontrolled diabetes during research, the need for medication or dose modification that may disrupt the study process, unwillingness to continue cooperation and death. 


\section{Study design and intervention}

CONSORT checklist was used in this double-blind randomized parallel-group clinical trial (16), the research protocol was approved by the ethics committee of the Islamic Azad University, Science and Research Branch of Tehran, Iran (IR.IAU.SRB.REC.1396.83) and the RCT protocol was registered at ClinicalTrials.gov and it is available using NCT03589690 code. After obtaining informed consent from patients referred to the specialized obesity and nutritional clinic where their metabolic syndrome had been diagnosed by the specialists, 46 patients participated in the study, 23 patients in both groups received the supplement and placebo respectively, 4 participants who were excluded from the study for various reasons, for example, unwillingness to continue cooperation and taking less than $90 \%$ of the tested capsules. Finally, 42 subjects were randomly divided into two groups of intervention $(n=23)$ and control $(n=19)$ that received supplements and placebo for 12 weeks and completed different stages of the study (Fig. 1). The case group received a capsule of ALA (600 mg), and the control group was given a capsule of a starch-filled placebo (600 mg) every day. Initially, the boxes containing the relevant capsules were coded as $A$ and $B$ by someone outside the research team to make the investigators unable to know the type of capsule received by each group. At the end of the 12th week, the remaining capsules were counted to assess the patients' adherence to taking the capsules. The patients who took less than $90 \%$ of their capsules were excluded from the study. Patients were contacted once a week to monitor their drug consumption.

\section{Blood collection and glycemic control assessments}

To evaluate the biochemical factors, participants were asked to attend the Laboratory at the beginning and end of the study on the day of sampling after 8 to 12 hours of nocturnal fasting. Therefore, serum fasting glucose, serum triglycerides, glycosylated hemoglobin, and serum insulin were measured from $10 \mathrm{ml}$ of venous blood samples. Then, the collected blood samples were centrifuged at $3000 \mathrm{rpm}$ and kept at $-80^{\circ} \mathrm{C}$ until the examination. Blood glucose concentration was measured by the Enzymatic Calorimetric method and $\mathrm{HbA1c}$ was measured by the immunoturbidimetric method with Hemoglobin A1c kit (Roche Company) LOT-Number $=05336163$ and COBAS INTEGRA system. Serum insulin levels were also determined using the ELISA commercial kit (Demeditec Inc.) with LOT-N = 44K038. The HOMAIR index was used to calculate the insulin resistance level, as the following Eq. (12):

HOMA-IR $=\frac{\text { fastingglucose }\left(\frac{\mathrm{mg}}{\mathrm{dl}}\right) \times \text { fastingInsulin }\left(\frac{\mu \mathrm{u}}{\mathrm{ml}}\right)}{405}$

All of them were used at the beginning and end of the study. The this index has been confirmed in many studies $(17,18)$

\section{Anthropometric measurements and physical activity level}


According to the World Health Organization (WHO) standards, weights were measured with minimum coverage, without shoes, by using a Seca digital scale with an accuracy of $100 \mathrm{~g}$. Heights were measured without shoes by a meter mounted to the wall with an accuracy of $0.1 \mathrm{~cm}$. Then, the body mass index (BMI) was calculated by dividing weight per kilogram by height in square meters $\left(\mathrm{kg} / \mathrm{m}^{2}\right)$. The waist circumference (WC) was measured in the narrowest part between the lowest rib and the iliac crest. Physical activity (PA) data were collected using a short physical activity questionnaire with the validity and reliability of the Persian version (19). Demographic data were collected through a general information questionnaire at the beginning of the study.

\section{Dietary intake information}

To study the diet of patients at the beginning of the study, the patients were interviewed to complete the 24- hour recall for three days (two weekdays and a weekend day). Dietary factors affecting blood parameters were studied. Dietary intake information was obtained using N4 software and the daily intake of each individual was determined for total energy, carbohydrate, protein, and fat.

\section{Statistical analysis}

The normality of data distribution was analyzed by the Shapiro-Wilk test. A Paired-sample t-test was used to compare the average of quantitative variables with normal distribution in each group before and after the intervention. An independent sample t-test was utilized to compare the difference in quantitative variables between the intervention and placebo groups before and after the intervention. A Chi-square test was used to compare qualitative variables into two groups. The corresponding nonparametric test was used for data with an unusual distribution. The analysis of the covariance test was performed to adjust the effects of confounding factors in this study. Data were analyzed using SPSS-24 software. The test power of 0.8 , as well as $\mathrm{P}<0.5$, was considered as statistically significant.

\section{Results}

The present study was conducted on 42 patients with metabolic syndrome ( 23 cases receiving ALA and 19 cases in control group). The dropout rate was less than $15 \%$ in the placebo group $(n=4)$. They were excluded from the study due to the following reasons: unwillingness to continue cooperation $(n=2)$, taking less than $90 \%$ of the tested capsules

$(n=1)$, and immigration abroad $(n=1)($ Fig. 1$)$.

The demographic characteristics and dietary intake among the participants at the baseline of the study are listed in Table 1, and also these analyzed variables showed no significant differences between the intervention and control groups in terms of age $(P=0.11)$, sex

$(P=0.76)$, weight $(P=0.74)$, height $(P=0.25)$, $B M I(P=0.23)$, WC $(P=0.32)$, Total Energy Intake $(P=0.59)$, carbohydrate $(\mathrm{CHO})$ Intake $(P=0.29)$, Protein Intake $(P=0.57)$, Fat Intake $(P=0.06)$, and $P A(P=0.63)$ 
(Table 1). At the end of this study, it was a significant decrease in the mean changes in FBS $(P=0.009)$, serum insulin $(P=0.02)$, and insulin resistance

$(P=0.001)$ between the two groups while it was no significant difference between the two groups in HbA1c percentage $(P=0.16)$ (Table 2).

Table 1

Demographic characteristics and dietary intake of the study participants by alpha-lipoic acid or placebo groups

\begin{tabular}{|c|c|c|c|}
\hline Parameters & $\begin{array}{l}\text { ALA }(600 \mathrm{mg}) \\
(\mathrm{n}=23)\end{array}$ & $\begin{array}{l}\text { Control } \\
(n=19)\end{array}$ & p. value \\
\hline Age (years old) & $40.39 \pm 8.90$ & $43.68 \pm 3.52$ & $0.11^{\mathrm{a}}$ \\
\hline Gender (female/male) & $(16 / 7)$ & $(14 / 5)$ & $0.76^{b}$ \\
\hline Weight (kg) & $96.58 \pm 30.66$ & $93.73 \pm 16.81$ & $0.74^{\mathrm{c}}$ \\
\hline Height $(\mathrm{Cm})$ & $164.76 \pm 8.54$ & $166.61 \pm 9.10$ & $0.25^{\mathrm{a}}$ \\
\hline $\mathrm{BMI}\left(\mathrm{kg} / \mathrm{m}^{2}\right)$ & $34.98 \pm 8.29$ & $35.35 \pm 4.23$ & $0.23^{\mathrm{c}}$ \\
\hline WC $(\mathrm{Cm})$ & $113.30 \pm 20.40$ & $115.63 \pm 9.49$ & $0.32^{\mathrm{c}}$ \\
\hline Total Energy Intake (Kcal/day) & $2116.83 \pm 582.53$ & $2026.42 \pm 502.83$ & $0.59^{a}$ \\
\hline $\mathrm{CHO}$ Intake (gr/day) & $259.50 \pm 86.48$ & $288.48 \pm 91.20$ & $0.29^{\mathrm{a}}$ \\
\hline Protein Intake (gr/day) & $80.12 \pm 26.16$ & $75.83 \pm 21.65$ & $0.57^{\mathrm{a}}$ \\
\hline Fat Intake (gr/day) & $80.57 \pm 22.53$ & $65.90 \pm 18.09$ & $0.06^{\mathrm{a}}$ \\
\hline PA (High/ Moderate/ low) & $5 / 5 / 13(21.7 / 21.7 / 56.5)$ & $5 / 6 / 8(31.5 / 26.3 / 42.1)$ & $0.63^{b}$ \\
\hline \multicolumn{4}{|c|}{ All values were reported as Mean \pm S.D. ${ }^{*} \mathrm{P}<0.05$ was considered as statistically significant } \\
\hline \multicolumn{4}{|l|}{ Abbreviations: } \\
\hline \multicolumn{4}{|c|}{$\begin{array}{l}\text { ALA, alpha-lipoic acid; BMI, body mass index; WC, waist circumference; PA, physical activity; } \mathrm{CHO} \text {, } \\
\text { carbohydrate. }\end{array}$} \\
\hline \multicolumn{4}{|c|}{ a It was tested using Independent - Samples T Test. } \\
\hline
\end{tabular}

${ }^{\mathrm{c}}$ It was tested using Independent - samples Mann - Whitney U Test. 
Table 2

Mean, standard deviation and changes of glycemic control in the study groups

\begin{tabular}{|c|c|c|c|c|c|c|c|}
\hline \multirow[t]{2}{*}{ Variable } & \multicolumn{3}{|c|}{$\begin{array}{l}\text { ALA (600 mg) } \\
(n=23)\end{array}$} & \multicolumn{4}{|l|}{$\begin{array}{l}\text { Control } \\
(n=19)\end{array}$} \\
\hline & Baseline & $\begin{array}{l}\text { 12th } \\
\text { week }\end{array}$ & $\begin{array}{l}\text { Average } \\
\text { changes }\end{array}$ & Baseline & $\begin{array}{l}\text { 12th } \\
\text { week }\end{array}$ & $\begin{array}{l}\text { Average } \\
\text { changes }\end{array}$ & $\begin{array}{l}P \\
\text { value } \\
c\end{array}$ \\
\hline $\mathrm{FBS}(\mathrm{mg} / \mathrm{dL})$ & $\begin{array}{l}107.78 \\
\pm 46.04\end{array}$ & $\begin{array}{l}96.47 \pm \\
46.99\end{array}$ & $\begin{array}{l}-16.25 \pm \\
34.79 a *\end{array}$ & $\begin{array}{l}96.84 \pm \\
31.23\end{array}$ & $\begin{array}{l}105.42 \\
\pm 16.64\end{array}$ & $\begin{array}{l}8.57 \pm \\
21.05^{a *}\end{array}$ & $0.009 *$ \\
\hline $\begin{array}{l}\text { Serum } \\
\text { Insulin } \\
(\mu \mathrm{lU} / \mathrm{ml})\end{array}$ & $\begin{array}{l}12.99 \pm \\
4.76\end{array}$ & $\begin{array}{l}11.69 \pm \\
4.19\end{array}$ & $\begin{array}{l}-1.30 \pm \\
2.08^{b *}\end{array}$ & $\begin{array}{l}11.54 \pm \\
4.16\end{array}$ & $\begin{array}{l}11.39 \pm \\
3.85\end{array}$ & $\begin{array}{l}-0.14 \pm \\
0.8\end{array}$ & $0.02 *$ \\
\hline HbA1c (\%) & $\begin{array}{l}6.12 \pm \\
1.42\end{array}$ & $\begin{array}{l}6.30 \pm \\
1.5\end{array}$ & $\begin{array}{l}0.17 \pm \\
0.31^{a *}\end{array}$ & $\begin{array}{l}6.54 \pm \\
1.17\end{array}$ & $\begin{array}{l}6.30 \pm \\
0.74\end{array}$ & $\begin{array}{l}-0.24 \pm \\
1.35\end{array}$ & 0.16 \\
\hline $\begin{array}{l}\text { HOMA-IR } \\
\text { (score) }\end{array}$ & $\begin{array}{l}3.24 \pm \\
1.18\end{array}$ & $\begin{array}{l}2.65 \pm \\
1.16\end{array}$ & $\begin{array}{l}-0.58 \pm \\
0.599^{b^{*}}\end{array}$ & $\begin{array}{l}2.74 \pm \\
1.26\end{array}$ & $\begin{array}{l}2.92 \pm \\
0.94\end{array}$ & $\begin{array}{l}0.18 \pm \\
0.73\end{array}$ & $0.001 *$ \\
\hline \multicolumn{8}{|c|}{ All values were reported as Mean \pm S.D. ${ }^{*} P<0.05$ was considered as statistically significant } \\
\hline \multicolumn{8}{|c|}{$\begin{array}{l}\text { Abbreviations: ALA, alpha-lipoic acid: FBS, Fasting blood sugar; HOMA-IR, Homeostatic model } \\
\text { assessment insulin resistance; HbA1c, Hemoglobin A1c or Glycated hemoglobin }\end{array}$} \\
\hline \multicolumn{8}{|c|}{ a It was tested using Wilcoxon Signed Rank Test. } \\
\hline \multicolumn{8}{|c|}{ b It was tested using Paired Samples T Test. } \\
\hline tonto & Inde & $\mathrm{t}-$ & $S T T$ & & & & \\
\hline
\end{tabular}

\section{Discussion}

In the present study, the administration of $600 \mathrm{mg}$ of ALA for 12 weeks resulted in a significant decrease in FBS, serum insulin, and insulin resistance in the patients with metabolic syndrome between the two groups; however, no significant change was observed in the HbA1c level.

Favorable results were reported in the Ansar et al.'s study that were in agreement with our study, and after 8 weeks of $300 \mathrm{mg}$ ALA administration, a significant decrease was observed in mean FBS changes and insulin resistance between the intervention and control groups at the end of the study (20). Also, in the Mazloum et al.'s study, the results were in line with the present study such as a significant decrease in fasting blood glucose after 8 weeks and intake of $300 \mathrm{mg}$ ALA but no significant difference was observed in HbA1c (21). In another study consistent with our study performed by Vasdev et al.in mice, after 9 weeks of intervention on mice receiving $500 \mathrm{mg} / \mathrm{kg}$ ALA, a decrease was observed in blood glucose and insulin levels (22). 
According to previous studies, the ALA is a potent factor in lowering the blood sugar level $(13,20,21)$. In fact, the ALA through increasing the activity of enzymes and complexes in the electron transport chain in the mitochondria, accelerates the Krebs cycle, and through activating pyruvate dehydrogenase accelerates glucose oxidation up to 1.5 -fold. On the other hand, the ALA through increasing the activity of Adenosine monophosphate -activated protein kinase (AMPK) causes an increase in the oxidation of free fatty acids and also a decrease in the accumulation of lipid and triglyceride in muscle tissue, which result in peripheral blood glucose intake $(23,24)$. Glucose uptake by ALA is associated with the redistribution of glucose transporter (Glut) 1 and Glut 4 transporters inside the cell (25).

The ALA has a positive effect on glucose uptake by insulin stimulation (26). In a study by Khamaisi conducted on streptozotocin -induced diabetic rats, the blood glucose concentration was reduced after the injection of ALA (30 mg / kg) for 10 days, and the intra-membrane GluT4 protein level increased up to 2.8-fold (11). Empirical findings indicated that, ALA mimics the insulin function through affecting the insulin signaling pathway. This stimulatory effect is associated with the activation of phosphoinositide 3kinase $(\mathrm{PI} 3 \mathrm{~K})$ and protein kinase $\mathrm{B}(\mathrm{PKB})$ or Akt pathways. Long-term treatment with ALA supplementation is also associated with the decreased plasma insulin levels. Moreover, stimulation of tyrosine phosphorylation at the insulin receptor is another role of ALA. During the recovery after exercise and after meals containing carbohydrates, the blood insulin concentration increased in response to the elevated blood sugar. The insulin binds to its specific receptor in the target cell, thereby modulating the intracellular activity. The insulin binding to the outer subunit of receptor leads to conformation in the integral membrane subunit, and this subunit has enzymatic properties (tyrosine kinase). Activated subunits affix phosphate groups to the cytoplasmic domain of receptor and also to a group of insulin receptor substrate (IRS). Then, the activated IR phosphorylates insulin receptor substrate-1 (IRS-1) and other substrates. Next, the IRS-1 acts as a binding protein for PI3K that was activated by this process. The hierarchies initiated by PI3K include the activation of PI3K-dependent kinases (PDK) and Akt signaling molecule. The Akt, also known as PKB, can mediate many insulin activities including glycogen synthase activation, Glut 4 transportation from vesicles to plasma membranes for glucose transport, and induction of protein synthesis. In fact, in this process, the ALA supplementation facilitates the insulin-receptor complex and promotes the formation of integral membrane subunits as tyrosine kinase (27).

The results of this study are consistent with previous studies showing that, ALA may decrease the insulin resistance and increase the insulin sensitivity $(8,28,29)$. In a study by Jacob et al., the patients with type II diabetes consumed the ALA supplement (600 mg and $1000 \mathrm{mg}$ daily) for 10 days, and the findings showed that, the insulin sensitivity improved and the insulin-mediated glucose depletion increased. In fact, the ALA enhances the capacity of the glucose transport system through insulin induction, as well as triggering both oxidative and non-oxidative pathways of glucose metabolism in the insulin-resistant muscles (8). The ALA had prominent effects on liver function because the ALA decreased the rate of gluconeogenesis from precursors such as lactate, pyruvate, alanine, and glycerol in hepatocytes isolated from starved laboratory rats. This effect of ALA on the reduction of glucose production, aids the capture of coenzyme $A$ in mitochondria and inhibits carbon flow through the gluconeogenic pathway in these cells (30). In general, in the diabetic laboratory rats with hyperglycemia and insulin deficiency, the alpha- 
lipoic acid can lower the blood glucose levels by increasing the activity of glucose transporters in the skeletal muscle and decreasing the glucose production in the liver, and finally by elevating the glucose tolerance in these animals $(11,31,32)$

Siti Balkis (2008) reported a significant decrease in HbA1c levels in the diabetic rats after 8 weeks of ALA supplementation (33). Although some researchers found a significant difference in glycosylated hemoglobin levels $(13,34)$, in this study, the glycosylated hemoglobin level showed no significant decrease in the blood glucose levels. In a study by Manning PJ et al., FBS levels, serum insulin, and insulin resistance did not significantly change during the study (35), and these results are inconsistent with our study, which could be due to the differences in durations of studies, sample sizes, ALA levels or administration methods between the present study and the two above-mentioned studies. Therefore, it is recommended that, future studies may investigate the effects of ALA supplementation on dosage, duration of study, and sample size in the patients with chronic diseases.

\section{Conclusion}

The results of the present study show that, the administration of $600 \mathrm{mg}$ of ALA alone for 12 weeks might be able to improve the blood glucose levels, serum insulin and insulin resistance. Therefore, the ALA, as a potent antioxidant will have positive effects on promoting the health levels in the patients with metabolic syndrome.

\section{Abbreviations}

ALA: Alpha-lipoic acid; FBS: Fasting blood sugar; HbA1c: Hemoglobin A1c or hemoglobin glycated; N4: Nutritionist 4; NCEP ATPIII: National cholesterol education program adult treatment panel III criteria; WHO: World health organization; BMI: Body mass index; WC: Waist circumference; PA: Physical activity; CHO: carbohydrate; HOMA-IR: Homeostatic model assessment insulin resistance; AMPK: Adenosine monophosphate -activated protein kinase; Glut: glucose transporter; PI3K: Phosphoinositide 3-kinase; PKB: Protein kinase B; IRS: Insulin receptor substrate; PDK: PI3K-dependent kinases.

\section{Declarations}

\section{Ethics approval and consent to participate}

The study was approved by the ethics committee of the Islamic Azad University, Science and Research Branch of Tehran, Iran (IR.IAU.SRB.REC.1396.83).

\section{Consent for publication}

All authors approved the publication of the manuscript in the Nutrition Journal.

\section{Availability data and materials}




\section{Competing interest}

All authors declare that they have no competing interest.

\section{Funding}

Not applicate.

\section{Authors' contributions}

We declare that this manuscript has been composed with agreement by all authors and that the work has not been published elsewhere. We confirm that the work submitted is our own and contribution of each author to this work has been explicitly indicated below.

\section{Acknowledgments}

The current article has been adapted from the MSc thesis in Nutrition Sciences entitled "effect of alphalipoic acid supplementation on glycemic control and anthropometric indices in the patients with metabolic syndrome". The authors would like to thank and appreciate all the contributors to this study and all who helped us in conducting this research.

\section{References}

1. Kaur J. A comprehensive review on metabolic syndrome. Cardiology research practice. 2014;21:2014. doi:10.1155/2014/943162.

2. Ghergherehchi R, Razaghi Azar M. Metabolic syndrome prevalence in obese children and adolescents. Medical Journal of Tabriz University of Medical Sciences. 2010;32(3):57-61. doi:10.19082/5402.

3. Amiri A, Hakimi A. The study of prevalence of metabolic syndrome among nurses of Shahid Mohammadi Hospital of Bandar Abbas city, Iran. Journal of Clinical Nursing and Midwifery. 2017;6.

4. Eckel RH, Alberti K, Grundy SM, Zimmet PZ. The metabolic syndrome. The Lancet. 2010;375(9710):181-3. doi:10.1016/S0140-6736(09)61794-3.

5. Alexander CM. The coming of age of the metabolic syndrome. Diabetes Care. 2003;26(11):3180-1. doi:10.2337/diacare.26.11.3180.

6. Cameron AJ, Shaw JE, Zimmet PZ. The metabolic syndrome: prevalence in worldwide populations. Endocrinol Metab Clin North Am. 2004;33(2):351-75. 
7. Packer L, Witt EH, Tritschler HJ. Alpha-lipoic acid as a biological antioxidant. Free radical biology medicine. 1995;19(2):227-50. doi:10.1016/0891-5849(95)00017-R.

8. Jacob S, Ruus P, Hermann R, Tritschler H, Maerker E, Renn W, et al. Oral administration of RAC-alipoic acid modulates insulin sensitivity in patients with type-2 diabetes mellitus: a placebocontrolled pilot trial. Free Radic Biol Med. 1999;27(3-4):309-14. doi:10.1016/S08915849(99)00089-1.

9. Thirunavukkarasu V, Anitha Nandhini A, Anuradha C. Lipoic acid improves glucose utilisation and prevents protein glycation and AGE formation. Die Pharmazie-An International Journal of Pharmaceutical Sciences. 2005;60(10):772-5.

10. Ansar H, Mazloum Z, Ghaem H. The effect of alpha-lipoic acid on insulin resistance in type 2 diabetic patients. Journal of Birjand University of Medical Sciences. 2009;16(4):5-12.

11. Khamaisi M, Potashnik R, Tirosh A, Demshchak E, Rudich A, Trischler H, et al. Lipoic acid reduces glycemia and increases muscle GLUT4 content in streptozotocin-diabetic rats. Metabolism. 1997;46(7):763-8. doi:10.1016/S0026-0495(97)90120-7.

12. Daneshi-Maskooni M, Keshavarz SA, Qorbani M, Mansouri S, Alavian SM, Badri-Fariman M, et al. Green cardamom supplementation improves serum irisin, glucose indices, and lipid profiles in overweight or obese non-alcoholic fatty liver disease patients: a double-blind randomized placebocontrolled clinical trial. BMC Complement Altern Med. 2019;19(1):59. doi:10.1186/s12906-019-24650 .

13. Yaworsky K, Somwar R, Ramlal T, Tritschler H, Klip A. Engagement of the insulin-sensitive pathway in the stimulation of glucose transport by a-lipoic acid in 3T3-L1 adipocytes. Diabetologia. 2000;43(3):294-303. doi:10.1007/s001250050.

14. Gorąca A, Huk-Kolega H, Piechota A, Kleniewska P, Ciejka E, Skibska B. Lipoic acid-biological activity and therapeutic potential. Pharmacological Reports. 2011;63(4):849-58. doi:10.1016/s17341140(11)70600-4.

15. Han T, Bai J, Liu W, Hu Y. Therapy of Endocrine Disease: A systematic review and meta-analysis of alipoic acid in the treatment of diabetic peripheral neuropathy. European journal of endocrinology. 2012;167(4):465-71. doi:10.1530/EJE-12-0555.

16. Moher D, Hopewell S, Schulz KF, Montori V, Gøtzsche PC, Devereaux P, et al. CONSORT 2010 explanation and elaboration: updated guidelines for reporting parallel group randomised trials. International journal of surgery. 2012;10(1):28-55. doi:10.1016/j.jjsu.2011.10.001.

17. Bonora E, Kiechl S, Willeit J, Oberhollenzer F, Egger G, Targher G, et al. Prevalence of insulin resistance in metabolic disorders: the Bruneck Study. Diabetes. 1998;47(10):1643-9. doi:10.2337/diabetes.47.10.1643.

18. Sarafidis P, Lasaridis A, Nilsson P, Pikilidou M, Stafilas P, Kanaki A, et al. Validity and reproducibility of HOMA-IR, 1/HOMA-IR, QUICKI and McAuley's indices in patients with hypertension and type II diabetes. J Hum Hypertens. 2007;21(9):709-16. doi:10.1038/sj.jhh.1002201. 
19. Montazeri A, Goshtasebi A, Vahdaninia M, Gandek B. The Short Form Health Survey (SF-36): translation and validation study of the Iranian version. Quality of life research. 2005;14(3):875-82. doi:10.1007/s11136-004-1014-5.

20. Ansar H, Mazloom Z, Kazemi F, Hejazi N. Effect of alpha-lipoic acid on blood glucose, insulin resistance and glutathione peroxidase of type 2 diabetic patients. Saudi Med J. 2011;32(6):584-8.

21. Mazloom Z, Ansar H, Karimi F, Kazemy F. The antioxidative effect of alpha-lipoic acid on blood glucose concentration and $\mathrm{HbA} 1 \mathrm{C}$ in type 2 diabetic patients. Journal of Gorgan University of Medical Sciences. 2009;11(2).

22. Vasdev S, Ford CA, Parai S, Longerich L, Gadag V. Dietary a-lipoic acid supplementation lowers blood pressure in spontaneously hypertensive rats. Journal of hypertension. 2000;18(5):567-73. doi:10.1097/00004872-200018050-00009.

23. Anderson J. Diabetes mellitus: medical nutrition therapy. Modern Nutrition in Health and Disease Philadelphia: Lea \& Febiger. 2006:1043-66.

24. Midaoui AE, de Champlain J. Prevention of hypertension, insulin resistance, and oxidative stress by a-lipoic acid. Hypertension. 2002;39(2):303-7. doi:10.1161/hy0202.104345.

25. Onay-Besikci A, Wagg C, Lopaschuk TP, Keung W, Lopaschuk GD. a-Lipoic acid increases cardiac glucose oxidation independent of AMP-activated protein kinase in isolated working rat hearts. Basic Res Cardiol. 2007;102(5):436. doi:10.1007/s00395-007-0661-4.

26. Khanna S, Roy S, Packer L, Sen CK. Cytokine-induced glucose uptake in skeletal muscle: redox regulation and the role of a-lipoic acid. American Journal of Physiology-Regulatory Integrative Comparative Physiology. 1999;276(5):R1327-R33. doi:10.1152/ajpregu.1999.276.5.R1327.

27. Cusi K, Maezono K, Osman A, Pendergrass M, Patti ME, Pratipanawatr T, et al. Insulin resistance differentially affects the PI 3-kinase-and MAP kinase-mediated signaling in human muscle. J Clin Investig. 2000;105(3):311-20. doi:10.1172/JCI7535.

28. Henriksen EJ. Invited review: Effects of acute exercise and exercise training on insulin resistance. J Appl Physiol. 2002;93(2):788-96. doi:10.1152/japplphysiol.01219.2001.

29. Poirier P, Tremblay A, Broderick TL, Catellier C, Tancrède G, Nadeau A. Impact of moderate aerobic exercise training on insulin sensitivity in type 2 diabetic men treated with oral hypoglycemic agents: is insulin sensitivity enhanced only in nonobese subjects? Med Sci Monit. 2002;8(2):CR59-65.

30. Tirosh O, Roy S, Packer L. Lipoic acid, cellular metabolism, antioxidant activity and clinical relevance. Hand book of antioxidants. 2001;2:473-87.

31. Natraj C, Gandhi V, Menon K. Lipoic acid and diabetes: effect of dihydrolipoic acid administration in diabetic rats and rabbits. J Biosci. 1984;6(1):37-46. doi:10.1007/BF02702855.

32. Strödter D, Lehmann E, Lehmann U, Tritschler H-J, Bretzel R, Federlin K. The influence of thioctic acid on metabolism and function of the diabetic heart. Diabetes Res Clin Pract. 1995;29(1):19-26. doi:10.1016/0168-8227(95)01118-W.

33. Siti B, Khairul O, Wan Nazaimoon W, Faizah O, Santhana R, Mokhtar A, et al. Alpha lipoic acid reduces plasma glucose and lipid and the Ultra-Microscopic vascular changes in streptozotocin induced 
diabetic rats. Annals of Microscopy. 2008;8:58-65.

34. Evans P, Joseph L, Heymann P-C, Catherine J, Ira M, Gavin D, Laurence M. A. Pharmacokinetics, Tolerability, and fructosamine-lowering effect of a novel, controlled-release formulation of a-lipoic acid. Endocr Pract. 2002;8(1):29-35. doi:10.4158/EP.8.1.29.

35. Manning P, Sutherland W, Williams S, Walker R, Berry E, De Jong S, et al. The effect of lipoic acid and vitamin $\mathrm{E}$ therapies in individuals with the metabolic syndrome. Nutrition Metabolism Cardiovascular Diseases. 2013;23(6):543-9. doi:10.1016/j.numecd.2011.11.006.

\section{Figures}

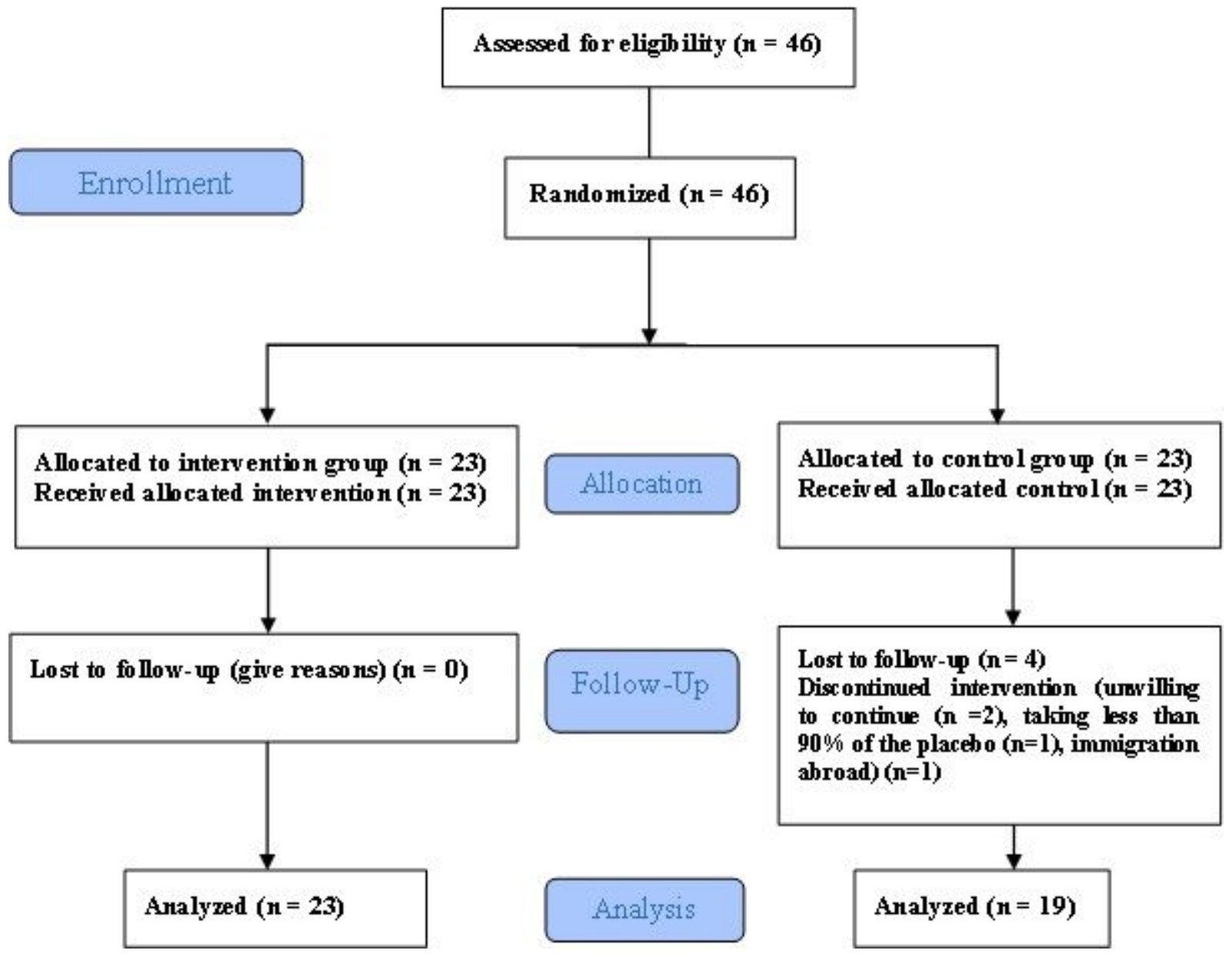

Figure 1

Study flow diagram 